\title{
A RECUPERAÇÃO JUDICIAL DAS COOPERATIVAS DE RELEVANTE PORTE ECONÔMICO: UM INSTRUMENTO PARA A EFETIVAÇÃO DOS DIREITOS FUNDAMENTAIS
}

\author{
Luiz César Martins Loques* \\ Leandro Abdalla Ferrer* \\ Flavio Edmundo Novaes Hegenberg*
}

\begin{abstract}
Resumo
O artigo considera a evolução histórica do direito comercial e a troca de seu objeto paradigma tendo como protagonista o mercado, em detrimento de concepções clássicas. O direito comercial, sob a égide da Constituição Brasileira de 1988, que trouxe à luz os direitos fundamentais, não pode ser letárgico e omitir-se em tutelar de forma efetiva e com bases democráticas, os meios mais aptos no auxílio da solução da crise econômico-financeira dos agentes de mercado; principalmente, quando suas atividades estão diretamente ligadas à concretização dos direitos fundamentais além do alcance do Estado.
\end{abstract}

Palavras-chave: Direitos Fundamentais, Mercado, Recuperação Judicial, Cooperativa, Cooperativismo e Economia.

\section{THE JUDICIAL RECOVERY OF COOPERATIVES WITH RELEVANT ECONOMIC SIZE: AN INSTRUMENT FOR EFFECTIVENESS OF FUNDAMENTAL RIGHTS}

\begin{abstract}
This text considers the historical evolution of commercial law and the exchange of its paradigm object with the market as the protagonist, to the detriment of the classic conceptions. The commercial law, under the aegis of the 1988 Brazilian Constitution, which brought fundamental rights to light, cannot be lethargic and neglect to act as guardian to, and, with democratic foundations, protect the most capable means of helping to solve the economic and financial crisis of market agents, especially when its activities are directly linked to the realization of fundamental rights beyond the grasp of the state.

\footnotetext{
*Advogado. Mestrando em Direito pelo Centro Universitário Salesiano de São Paulo (UNISAL). Pós-Graduando em Direito Empresarial e em Direito Notarial e Registral pela Faculdade Única de Ipatinga. Bacharel em Direito pelo Centro Universitário de Volta Redonda (UNIFOA). Professor dos cursos Jurismestre e Cepifar. Contato: Icloques@gmail.com (email).

*Advogado (Ferrer, Aon \& Vianna Sociedade de Advogados). Mestrando em Direito pelo Centro Universitário Salesiano de São Paulo (UNISAL). Especialista em Direito Administrativo pelo IED. Pós-Graduando em Direito Processual Aplicado pelo EPD. Bacharel em Direito pela Faculdade de São Lourenço. Professor do curso Jurismestre. Contato: leferrer13@yahoo.com.br (email).

*Doutor (PhD, Business Studies, 2001) pela University of Leeds, England (UK). Mestre em “Administração e Política de Recursos Minerais" pela Universidade Estadual de Campinas (UNICAMP, 1994). Geólogo pela Universidade do Estado do Rio de Janeiro (UERJ, 1987). Professor de Economia Política do curso de Direito do Centro Universitário de Volta Redonda (UNIFOA) de 2007 até 2019. Atualmente é membro da "The Development Studies Association" (www.devstud.org.uk), com sede no Reino Unido. Contato flavio.leeds@gmail.com (email).
} 
Keywords: Fundamental Rights, Market Economy, Judicial Recovery, Cooperative, Cooperatives and Economics.

\section{INTRODUÇÃO}

O presente trabalho visa demonstrar, diante do arcabouço doutrinário e jurisprudencial atual, a necessidade de superação de certos elementos que envolvem a aplicação dos institutos da Lei 11.101/2005. Mais especificamente: a flexibilização interpretativa de seus destinatários diretos, cuja incidência é impedida pelo Art. $2^{\circ}$ da referida lei.

As cooperativas, por suas diversas faces, e seu fortalecimento no escopo econômico, ganharam relevante papel no século XXI. Principalmente no cenário do direito privado, após o advento do CC/2002, que se tornou o centro interpretativo deste, a partir de sua edição e posterior vigência, graças ao pesado viés constitucional em sua interpretação, que é a tendência do direito privado moderno.

O direito comercial, como ramo autônomo do direito privado, não pode eximir-se de seu viés regulador e estruturador de mercados. Além, claro, de fornecer os instrumentos mais aptos a ensejar a estabilidade dos agentes econômicos pela via jurídica, independentemente da proporção de atividades destes.

O segundo capítulo dedica-se ao estudo das perspectivas gerais do direito cooperativo, analisando sua evolução histórica, as características que as diferenciam dos demais tipos de pessoas jurídicas de direito privado, reflexões acerca da Lei 5.764/1971 (que disciplina a matéria). Oferece também uma constatação sobre o crescente número de cooperativas atuando no âmbito do mercado nas mais diversas áreas.

O terceiro capítulo debruça-se sobre o papel relevante da evolução histórica do direito comercial; e como este tem importância em novas formas da interpretação da legislação falimentar vigente. No quarto capítulo analisa-se a recuperação judicial como um instrumento viável e mais eficiente para a cooperativa de relevante porte econômico em crise econômicofinanceira, principalmente, pelo grande impacto de algumas delas, se comparado com outros meios. Adota-se como foco de estudo deste capítulo as cooperativas de crédito e as cooperativas operadoras de planos de saúde. Questiona-se, então, a parcialidade e a eficiência dos órgãos federais para a condução do procedimento administrativo de liquidação extrajudicial. 
No quinto capítulo dá-se protagonismo à efetivação dos direitos fundamentais, uma vez que as cooperativas que possuem tal característica, gozando de mecanismos que proporcionem sua recuperação econômico-financeira mais efetiva, levam ao benefício direto dos cooperados que dependem, em caráter geral, dos produtos e serviços oferecidos por estas. E que estão ligados à concretização de diversos direitos fundamentais, fora da oferta estatal, como: direito à saúde, direito à alimentação, direito ao consumo, entre outros.

Reserva-se ao final, na conclusão, que algumas cooperativas, por sua relevância econômica e social na atualidade, devem possuir o direito ao procedimento recuperacional judicial. Além disso, as cooperativas, em alguns casos, dominam frações relevantes da atividade econômica nacional e competem diretamente com sociedades empresárias, que possuem direito por determinação legal, ao supracitado procedimento.

\section{PERSPECTIVAS GERAIS DO DIREITO COOPERATIVO}

Desde o início dos tempos os ideais do cooperativismo despertam interesse em nossa sociedade. Fátima Nancy Andrighi (2003, p. 49) afirma:

As ações cooperativistas datam de muitos séculos, conforme se depreende, inclusive, dos textos bíblicos, nos quais Jesus Cristo e seus apóstolos e, a posteriori, seus seguidores, praticavam o cooperativismo como ideologia de vida, pregando o bem comum acima de qualquer outro valor.

Caracteriza também Diva Pinho (1996, p. 17):

Em todos os tempos os homens têm se auxiliado mutuamente para remover um obstáculo ou se defender das intempéries. [...] A cooperação pode se apresentar de maneira informal ou formal. O primeiro caso verifica-se, frequentemente, nas zonas rurais, quando os vizinhos se reúnem em mutirão para preparar a terra, semear, colher, marcar o gado ou realizar outras atividades. O segundo caso aparece quando a entreajuda obedece a estatutos previamente elaborados pelos membros cooperados.

Os princípios basilares que norteiam o cooperativismo foram idealizados pelos precursores de Rochdale (na Inglaterra), nos idos de 1844, com o objetivo de melhorar as condições da classe operária oprimida. Constitui-se então uma sociedade formada por vinte e oito membros, visando organizar uma sociedade baseada na valorização do ser humano, na solidariedade, na busca do bem comum e na adesão voluntária, sem objetivo de lucro (valores incorporados, no Brasil, no Art. $3^{\circ}$ da Lei n. ${ }^{\circ}$ 5.764/1971). Nesse diapasão afirma Bialoskorski Neto (2006, p. 28):

[...] é considerado o início do movimento cooperativista mundial, ou seja, o marco fundamental do cooperativismo moderno. A base doutrinária dos estatutos desses cooperativistas pioneiros norteará toda organização cooperativa até os dias de hoje, 
sendo adotada e propagada pela Aliança Cooperativa Internacional e pelas organizações cooperativas em nível nacional.

Este progresso foi responsável pela rápida expansão do cooperativismo de consumo, com o surgimento da primeira lei regulamentando o funcionamento de cooperativas. Assim conclui Maria Cecília de Araújo Furquim (2001, p. 25):

Em 1852, surge a primeira Lei regulamentando o funcionamento das Cooperativas, "The Industrial and Provident Societies Act" com uma emenda, elaborada dez anos mais tarde, que (sic) assegurou à cooperativa a responsabilidade limitada e o direito a se federarem. Essa legislação foi utilizada como modelo para a regulamentação das cooperativas em outros países. A partir daí, as cooperativas na Inglaterra passaram a formar um grande movimento e em 1860 surgiu em Manchester o jornal "The Cooperator", responsável pela propaganda destas ideias, (órgão a serviço do movimento). Logo em seguida as sociedades cooperativas se organizaram numa grande Federação, que muito contribuiu para o progresso das cooperativas filiadas. $\mathrm{O}$ crescimento do número de cooperativas criadas na Inglaterra constituiu algo fenomenal.

Desta forma o cooperativismo passou a fazer parte do processo econômico na Europa, trazendo grandes modificações ao aspecto societário da época. Assim descreve Eduardo Harder (2005, p. 115):

Um aspecto peculiar que de fato contribuiu para a construção do perfil institucional das primeiras organizações cooperativas foi o fato delas terem sido, em alguns casos, o desdobramento das atividades das antigas corporações de ofício como as guildas e os trade clubs, que além do caráter profissional estavam revestidas de propósitos mutualistas ao manterem fundos comuns de solidariedade para atender a emergências como doenças e óbitos, tendo, assim, facilidade para criar outros fundos destinados a compras em comum ou mesmo aquisição dos meios de produção. Outro elemento importante foi o fato de que nesse conjunto de motivações e objetivos, os quais orientavam a ação dos trabalhadores ao constituírem as primeiras formas de organização cooperativa, revelou-se de fundamental importância a influência direta do "socialismo utópico" o que transpôs a discussão sobre o cooperativismo para uma seara política mais ampla, que visava a profundas reformas sociais.

Passadas as explicações exordiais da origem e princípios basilares da cooperativa, é importante trazer alguns conceitos do vocábulo 'cooperativa`. De acordo com De Plácido e Silva (1998, p. 15):

Derivada do latim cooperativus, de cooperare (cooperar, colaborar, trabalhar com outros), segundo o próprio sentido etimológico, é aplicado na terminologia jurídica para designar a organização ou sociedade, constituída por várias pessoas, visando melhorar as condições socioeconômicas de seus associados.

Renato Becho Lopes (2003, p. 22) conceitua:

Definimos a cooperativa como sendo a sociedade de pessoas, de cunho econômico, sem fins lucrativos, criada para prestar serviços aos sócios, de acordo com princípios jurídicos próprios e mantendo seus traços distintos intatos. 
As organizações existem para que haja melhor rendimento de trabalho entre seus membros. Nesse sentido Del Fiaco (2006, p. 67) argumenta que:

\begin{abstract}
Organizações existem porque têm dentro delas pessoas que trabalham. Instituições podem ter as melhores máquinas, a mais avançada tecnologia, mas sem gente, não podem funcionar. Só há desempenho através do trabalho produtivo, é uma função essencial. As organizações da sociedade atual se tornam cada vez mais, os meios pelos quais os indivíduos buscam seu sustento, encontram seu acesso a um status social, à comunidade e à satisfação e realização pessoal.
\end{abstract}

Desta forma as cooperativas são uma forma de trabalho que alinha a eficiência e a eficácia, buscando resultados econômicos para seus cooperados. Luiz Inácio Gaiger (2013, p. 213) compreende que: “Assim, as cooperativas populares, oriundas de lutas sociais, ao contrário daquelas induzidas externamente, além de exibirem melhores indicadores econômicos, apresentavam maior solidariedade comunitária e maior inserção política na sociedade".

O fim primordial das sociedades cooperativas é a prestação de serviços aos cooperados; desta forma, não aufere receitas e tampouco possui despesas. Em conformidade com as disposições do Art. 80 da Lei n. ${ }^{\circ}$ 5.764/1971, "as despesas da sociedade serão cobertas pelos associados mediante rateio na proporção direta da fruição de serviços". Mesmo quando atua no mundo administrativo ou judicial, o faz em nome de seus cooperados, não em nome da sociedade. Atua como uma longa manus de seus cooperados.

Constituída legalmente na forma de sociedade cooperativa, submetida ao regime estabelecido na Lei n. ${ }^{\circ}$ 5.764/1971, a qual prevê, em seu Art. $4^{\circ}$, ser a mesma "sociedade de pessoas, com forma e natureza jurídica próprias, de natureza civil, não sujeita à falência, constituídas para prestar serviços aos associados" nas quais adquire especialmente realce o espírito da mutualidade, equivalente à reciprocidade das prestações entre a cooperativa e o cooperado, em oposição ao cunho eminentemente empresarial das demais sociedades.

Daí porque Pontes de Miranda (1965, p. 429) já ter prelecionado que: “[...] a sociedade cooperativa é aquela em que a pessoa do sócio passa à frente do elemento econômico e as consequências da pessoalidade da participação são profundas a ponto de torná-la espécie de sociedade".

Sua maior particularidade, portanto, em decorrência de sua natureza jurídica, é tanto a ausência de lucro quanto a preocupação com o social e bem-estar de seus cooperados, cuja repercussão no mundo jurídico é enorme, especialmente levando-se em conta ser uma 
prestadora de serviços aos seus cooperados. Assim o Art. $4^{\circ}$ da Lei n..$^{\circ}$ 5.764/71, distingue as cooperativas das demais formas de sociedade:

Art. $4^{\circ}$ As cooperativas são sociedades de pessoas, com forma e natureza jurídica próprias, de natureza civil, não sujeitas a falência, constituídas para prestar serviços aos associados, distinguindo-se das demais sociedades pelas seguintes características:

I - adesão voluntária, com número ilimitado de associados, salvo impossibilidade técnica de prestação de serviços;

II - variabilidade do capital social representado por quotas-partes;

III - limitação do número de quotas-partes do capital para cada associado, facultado, porém, o estabelecimento de critérios de proporcionalidade, se assim for mais adequado para o cumprimento dos objetivos sociais;

IV - incessibilidade das quotas-partes do capital a terceiros, estranhos à sociedade;

$\mathrm{V}$ - singularidade de voto, podendo as cooperativas centrais, federações e confederações de cooperativas, com exceção das que exerçam atividade de crédito, optar pelo critério da proporcionalidade;

VI - quorum para o funcionamento e deliberação da Assembleia Geral baseado no número de associados e não no capital;

VII - retorno das sobras líquidas do exercício, proporcionalmente às operações realizadas pelo associado, salvo deliberação em contrário da Assembleia Geral;

VIII - indivisibilidade dos fundos de Reserva e de Assistência Técnica Educacional e Social;

IX - neutralidade política e indiscriminação religiosa, racial e social;

$\mathrm{X}$ - prestação de assistência aos associados, e, quando previsto nos estatutos, aos empregados da cooperativa;

XI - área de admissão de associados limitada às possibilidades de reunião, controle, operações e prestação de serviços.

Desta maneira, os membros vão contribuindo para o desenvolvimento da cooperativa.

Assim explica Flávio Augusto Dumont Pereira (2005, p. 46):

Os membros contribuem equitativamente para o capital das suas cooperativas e controlam-no democraticamente. Parte desse capital é, normalmente, propriedade comum da cooperativa. Os membros recebem, habitualmente, se houver, uma remuneração limitada ao capital integralizado, como condição de sua adesão. Os membros destinam os excedentes a uma ou mais das seguintes finalidades: desenvolvimento das suas cooperativas, eventualmente através da criação de reservas, parte das quais, pelo menos será, indivisível; benefício aos membros na proporção das suas transações com a cooperativa; apoio a outras atividades aprovadas pelos membros.

Assim, na medida em que um dos associados não honra seu compromisso, ou não observa normas Estatutárias da cooperativa, está a contribuir para que não atenda a seus objetivos sociais de distribuir adequadamente o crédito junto aos demais associados, pois, com a inadimplência, fica privada de recursos que seriam destinados aos demais associados.

No setor agropecuário temos 1613 cooperativas, com mais de um milhão de cooperados, gerando aproximadamente duzentos e dez mil empregos; no ramo de consumo, temos 205 cooperativas, com cerca de dois milhões de cooperados, gerando pouco mais de quatorze mil empregos; na área de setor de crédito se tem 909 cooperativas, com quase dez 
milhões de cooperados, gerando sessenta e sete mil empregos; no campo educacional temos 265 cooperativas, com mais de sessenta mil cooperados, gerando quase três mil e quinhentos empregos; no plano habitacional temos 282 cooperativas, mais de cem mil cooperados, gerando quase setecentos e cinquenta empregos; na categoria de infraestrutura são 135 cooperativas, mais de um milhão de cooperados e mais de cinco mil e quinhentos empregados; no ramo da saúde tem-se 786 cooperativas, mais de duzentos e seis mil cooperados, dando emprego a mais de cem mil pessoas; no âmbito do trabalho temos 925 cooperativas, com quase duzentos mil cooperados, gerando mais de cinco mil empregos; já no ramo do transporte, são 1351 cooperativas, quase cem mil cooperados e quase dez mil empregados (SISTEMA OCB, 2018, s/p).

Cada vez mais, no Brasil, cresce o número de cooperativas de diversos ramos de atividades econômicas. De acordo com dados do Sistema OCB (2018, s/p), o número de cooperativas no Brasil no ano de 2018 (somadas todas as cooperativas no Brasil no ano de 2018), atinge o total de 6828 cooperativas, quase quinze milhões de cooperados, gerando mais de quatrocentos mil empregos no país.

\section{O MERCADO COMO NOVO OBJETO DO DIREITO COMERCIAL}

O Art. $2^{\circ}$ da Lei 11.101/2005 dispõe que:

Art. $2^{\circ}$ Esta Lei não se aplica a:

I - empresa pública e sociedade de economia mista;

II - instituição financeira pública ou privada, cooperativa de crédito, consórcio, entidade de previdência complementar, sociedade operadora de plano de assistência à saúde, sociedade seguradora, sociedade de capitalização e outras entidades legalmente equiparadas às anteriores.

Percebe-se que pela redação da lei recuperacional e falimentar em vigência no país, duas atividades economicamente relevantes protagonizadas por cooperativas são excluídas: as cooperativas de crédito e as cooperativas operadoras de planos de saúde.

Para além desta regra, a Lei 11.101/2005 em seu artigo inaugural é bastante clara quanto à sua aplicação exclusiva para as sociedades empresárias e ao empresário individual: "Art. 1": Esta Lei disciplina a recuperação judicial, a recuperação extrajudicial e a falência do empresário e da sociedade empresária, doravante referidos simplesmente como devedor”.

Alguns argumentos ligados à própria dogmática e evolução do direito comercial justificam maior abrangência legal do conceito de empresário no instituto da recuperação 
judicial. É notório que as bases teóricas que suportaram o direito comercial em suas investigações ao longo dos séculos sofreram radicais modificações, como ocorreu com a passagem da primeira fase subjetiva de um direito ainda mercantil corporativista para a teoria dos atos de comércio (de índole objetiva) marcante no século XVIII. Destaca Tullio Ascarelli (2007, p. 86-87) sobre essa passagem:

A um direito diferenciado segundo as diversas classes sociais sucede assim um direito que podemos denominar objetivo, que esquece diferenças subjetivas, considerando somente a objetividade de cada um dos atos, em harmonia, por um lado com o princípio da igualdade jurídica dos cidadãos e por outro com a Soberania e unidade do Estado, paralelamente com a afirmação do conceito de nação como comunidade fundada em uma vontade comum.

Mais adiante, esse sistema objetivo também é superado, já que pela conveniência da atividade econômica predominante no século XIX, e pelas dificuldades de definir claramente sua abrangência para diferenciar os atos mercantis dos não mercantis, optou-se pela troca do "ato" unicamente, pela figura organizadora da empresa, levando-se em conta a lógica da “atividade”. Nesse sentido, constata Alfredo Assis Gonçalves Neto (2000, p. 47):

O principal argumento contrário ao sistema objetivo é justamente a precariedade científica da base em que se assenta - uma enumeração casuística de atos de comércio, feita pelo legislador ao acaso (de acordo com aquilo que a prática mercantil considerava, à época, pertencer ao Direito Comercial). Com isso, sequer se consegue encontrar o conceito de seu elemento fundamental, o ato de comércio.

Quanto à teoria da empresa supracitada, Ascarelli (1997, p. 269-271) é claro ao definir o elemento que embasaria essa nova fase:

E pois a natureza (e o exercício) da atividade que qualifica o empresário (e não, ao contrário, a qualificação do sujeito que determina a atividade) e nessa prioridade da atividade exercida para a qualificação do sujeito pode-se notar a persistência de u m elemento objetivo, como critério de aplicabilidade da especial disciplina ditada para a atividade e para quem a exerce.

Importa, por isso, determo-nos na análise do conceito de atividade, mesmo se alguns dos problemas que mencionaremos sob esse aspecto serão depois retomados na ilustração ulterior da doutrina do empresário.

A dinâmica da teoria da empresa com foco na atividade é uma realidade dos anos 40 do século XX, que ainda disponha de apoio da teoria de Asquini, que através de seus perfis da empresa, ainda via esta como um fenômeno estático (FORGIONI, 2018).

Para concretizar essa ideia de superação da estática da teoria da empresa, alguns autores já indicam um novo passo do direito comercial, com um novo objeto: o mercado. Paula A. Forgioni (2015, p. 73) dá luz à questão: 
Temos um novo período de evolução do direito comercial, em que se supera a visão estática de empresa para encará-la, também, em sua dinâmica. De um direito medieval de classe, ligado à pessoa do mercador, passamos ao critério objetivo e liberal dos atos de comércio e, finalmente, à atividade da empresa. Urge estudá-la a partir do pressuposto de que sua atividade somente encontra função econômica, razão de ser, no mercado.

Fomos "do ato à atividade". Agora, passamos ao reconhecimento de que a atividade das empresas conforma e é conformada pelo mercado. Enfim: ato, atividade, mercado". Eis a linha de evolução do direito comercial.

Se o objeto passa a ser o mercado, o fenômeno econômico passa a ter o protagonismo na interpretação do direito comercial. Nestes termos, realizando-se uma reflexão utilitarista, pouco importaria a análise da natureza estrita daquele agente de mercado que se submeteria aos institutos do direito comercial, o que importaria, de fato, seria a relevância de seu porte econômico e como estes poderiam auxiliá-lo.

O critério restritivo da Lei 11.101/2005 é desconexo da realidade prática, ainda enraizado no conceito de empresa do início do século XX, de um capitalismo marcadamente industrial e que não podia, pelos eventos históricos que o circunscreviam, prever que sociedades de natureza, não empresária ou civis, pudessem explorar ramos de alta complexidade econômica. Em outras palavras, a lei falimentar pátria prioriza o olhar puramente teórico-jurídico e ignora a realidade econômica pujante no país, o que de certa forma, limita o desenvolvimento daquelas.

Fábio Ulhoa Coelho (2003, p. 11) constata que se trata, exclusivamente, de opção legislativa:

As cooperativas, normalmente, dedicam-se às mesmas atividades dos empresários e costumam atender aos requisitos legais de caracterização destes (profissionalismo, atividade econômica organizada e produção ou circulação de bens ou serviços), mas, por expressa disposição do legislador, que data de 1971, não se submetem ao regime jurídico-empresarial. Quer dizer, não estão sujeitas à falência e não podem impetrar concordata. Ela é, sempre, uma sociedade simples e nunca, empresária.

Essa limitação não é só fruto da legislação esparsa; o próprio código civil brasileiro, em seu Art. 982, parágrafo único, ordenou que:

Art. 982. Salvo as exceções expressas, considera-se empresária a sociedade que tem por objeto o exercício de atividade própria de empresário sujeito a registro (art. 967); e, simples, as demais.

Parágrafo único. Independentemente de seu objeto, considera-se empresária a sociedade por ações; e, simples, a cooperativa.

O direito privado constitui-se em um microssistema de interação entre as normas, como define Flávio Tartuce (2017, p. 74): “Apesar da utilização da expressão microssistema, 
é fundamental apontar que essas leis especiais não são fechadas, estando a interação com as demais normas jurídicas, dentro de uma ideia unitária de sistema". Se o código civil e a legislação extravagante se direcionam em uníssono, a via legislativa está fossilizada.

Parte dos comercialistas, quando encontram conflitos entre a lei positiva e as práticas do mercado, ou até mesmo, entre a lei positiva e práticas que facilitariam o desempenho dos agentes de mercado, recorrem, geralmente, a usos e costumes, fontes primárias do direito comercial. Esta visão decorre de uma perspectiva em que o direito apenas traz ao plano da legalidade estatal as práticas de mercado, não sendo, de forma alguma, um agente de modificações no plano de atuação dos agentes econômicos (SZTAJN, 2010).

Independentemente de qualquer outra solução extrajudicial que se queira invocar para eximir-se da aplicação da legislação atual, deve-se reconhecer a imperatividade das normas cogentes do mercado, uma vez que a atuação dos agentes privados, através da autonomia da vontade, se restringe a estas (FORGIONI, 2018).

A única solução possível, no curto prazo e também no médio prazo, é a manifestação do judiciário nos casos concretos. Já foram registrados precedentes de deferimento do processamento de recuperações judiciais de cooperativas operadoras de planos de saúde. Na decisão que deferiu o processamento da recuperação judicial da Unimed Petrópolis, por exemplo, o juiz Jorge Luiz Martins Alves, vinculado ao Tribunal de Justiça do Estado do Rio de Janeiro (TJRJ, 2018, p. 623), compartilhou, de certa forma, desta linha de pensamento:

Vale dizer, portanto, com palavras distintas, mas que ostentam a mesma perspectiva
teleológica, que Unimed Petrópolis Cooperativa de Trabalho Médico está subjetiva e
objetivamente inserida na ambiência empresarial e que suas atividades têm natureza
de viés econômico. Com efeito, a jurisprudência dos conceitos (dogmática) impõe ao
intérprete/aplicador o dever de identificar as semelhanças e as distinções entre as
espécies elencadas no artigo $2^{\circ}$, I e II, Lei $11101 / 05$ e no artigo 23 , Lei $9656 / 98$,
sendo essa metodologia que nos permitirá imbricar as peculiaridades do que é
classificado como 'empresarialidade' com os meios etiológicos da 'atividade
econômica' que permeia o sistema (cooperativo), procedimento hermenêutico
destinado a identificar, em uma ponta, quais são os destinatários legais dos
benefícios de eventual repartição dos resultados financeiros da cooperativa e, na
outra ponta, a saber que são aqueles diretamente contemplados com a atividade-fim
do empreendimento cooperativo.

Denota-se que o magistrado, em primeiro lugar, priorizou o caráter econômico e da posição de mercado da cooperativa para o prosseguimento do procedimento recuperacional. Em complemento, o magistrado destacou a função social daquele agente econômico e seu impacto direto na vida dos que usufruem e até certo ponto, dependem, dada a essencialidade 
do serviço, de sua atividade. Em síntese, ponderou-se a função objetiva da cooperativa com o critério gélido da lei falimentar brasileira.

\title{
4. A RECUPERAÇÃO JUDICIAL COMO INSTRUMENTO DEMOCRÁTICO EM FACE DOS REGIMES EXTRAJUDICIAIS ADMINISTRATIVOS
}

$\mathrm{O}$ ordenamento jurídico brasileiro prevê procedimentos concursais administrativos alheios à legislação falimentar. Ricardo Negrão (2017, p. 645) justifica essa opção:

\begin{abstract}
O Estado reservou para si a autorização para funcionamento e a fiscalização de determinadas atividades de cunho empresarial, visando o controle de crédito público e evitando, dessa forma, os efeitos negativos sobre o sistema financeiro nacional ou áreas consideradas de grande interesse estratégico pelo Estado, quando essas empresas se encontrem em situação de inadimplência ou ofereçam perigo a depositantes, beneficiários do sistema e aplicadores do mercado.
\end{abstract}

A doutrina divide o rol do Art. $2^{\circ}$, I e II da lei falimentar, em casos de não incidência absoluta e relativa (NEGRÃO, 2017). Na incidência relativa, poderá ocorrer a aplicação da lei falimentar em algum momento do procedimento administrativo.

Adotando-se as cooperativas de crédito e as cooperativas operadoras de planos de saúde como objeto de estudo deste capítulo, uma vez que estas, fora do âmbito da atividade rural (que possui discussão própria, inclusive na jurisprudência do STJ), são os tipos de cooperativa com o grande porte econômico atuando no mercado nacional (VALOR ECONÔMICO, 2019).

Antes de adentrar propriamente nos casos peculiares a serem analisados, há posição minoritária defendida por parte da doutrina de que a Lei 11.101/2005 não deveria fazer diferença entre os tipos descritos no Art. $2^{\circ}$ (CASTRO, 2006).

As cooperativas de crédito possuem figura como instituições financeiras perante o sistema financeiro nacional. Essa previsão, inclusive, é clara na Lei 4.595/1964:

\footnotetext{
Art. 18. As instituições financeiras somente poderão funcionar no País mediante prévia autorização do Banco Central da República do Brasil ou decreto do Poder Executivo, quando forem estrangeiras.
}

$\S 1^{\circ}$ Além dos estabelecimentos bancários oficiais ou privados, das sociedades de crédito, financiamento e investimentos, das caixas econômicas e das cooperativas de crédito ou a seção de crédito das cooperativas que a tenham, também se subordinam às disposições e disciplina desta lei no que for aplicável [...].

Constata-se que as cooperativas de crédito figuram como uma atividade de grande porte econômico, já que segundo o estudo realizado pelo jornal Valor Econômico (2019, s/p), as cooperativas de crédito SICOOB e SICREDI ocupam o $8^{\circ}$ e o $10^{\circ}$ lugar, respectivamente, 
como maiores instituições financeiras do país no ano de 2018. Apenas em ativos a SICOOB possui $\mathrm{R} \$ 104.538,40$ (cento e quatro milhões quinhentos e trinta e oito mil reais e quarenta centavos), enquanto a SICREDI possui R \$ 95.072,80 (noventa e cinco milhões setenta e dois mil reais e oitenta centavos).

A grande questão, conforme argumentado anteriormente, é que as cooperativas de crédito enquanto tidas por instituições financeiras de acordo com a lei, submetem-se relativamente à legislação falimentar. Por essa razão, em um momento de crise econômicofinanceira que a impede de exercer regularmente suas atividades, estas inicialmente se submeterão ao procedimento da intervenção e/ou liquidação extrajudicial, conforme estabelece o Art.1 ${ }^{\circ}$ da Lei 6.024/1974:

Art . $1^{\circ}$ As instituições financeiras privadas e as públicas não federais, assim como
as cooperativas de crédito, estão sujeitas, nos termos desta Lei, à intervenção ou à
liquidação extrajudicial, em ambos os casos efetuada e decretada pelo Banco Central
do Brasil, sem prejuízo do disposto nos artigos 137 e 138 do Decreto-lei no ${ }^{\circ} 2.627$, de
26 de setembro de 1940, ou à falência,, nos termos da legislação vigente.

As cooperativas operadoras de planos de saúde, igualmente, são responsáveis por gerir uma atividade de grande porte econômico. Utilizando-se o mesmo estudo supracitado, verificou-se que, no mercado de planos de saúde no Brasil, a cooperativa Unimed está entre os 50 maiores operadores do país e ocupou, em 2018, 32 posições. O primeiro a constar na lista é a Unimed Rio que apresenta um ativo de R\$ 2.084.000,40 (dois milhões oitenta e quatro mil e quarenta centavos). Contudo, o patrimônio líquido da cooperativa representa um déficit de R\$ 945,3 milhões de reais (VALOR ECONÔMICO, 2019).

As operadoras de planos de saúde, por sua vez, não se submetem, em regra, ao regime da liquidação extrajudicial exclusivamente, de acordo com o Art.23 da Lei 9.656/1998:

Art. 23. As operadoras de planos privados de assistência à saúde não podem requerer concordata e não estão sujeitas a falência ou insolvência civil, mas tãosomente ao regime de liquidação extrajudicial. (Redação dada pela Medida Provisória n ${ }^{\circ} 2.177-44$, de 2001)

$\S 1^{\mathrm{o}}$ As operadoras sujeitar-se-ão ao regime de falência ou insolvência civil quando, no curso da liquidação extrajudicial, forem verificadas uma das seguintes hipóteses: (Incluído pela Medida Provisória nº 2.177-44, de 2001)

I - o ativo da massa liquidanda não for suficiente para o pagamento de pelo menos a metade dos créditos quirografários; (Incluído pela Medida Provisória $\mathrm{n}^{\circ}$ $\underline{2.177-44, \text { de 2001) }}$

II - o ativo realizável da massa liquidanda não for suficiente, sequer, para o pagamento das despesas administ rativas e operacionais inerentes ao regular 
processamento da liquidação extrajudicial; ou (Incluído pela Medida Provisória $\mathrm{n}^{\circ}$ $\underline{2.177-44, \text { de 2001) }}$

III - nas hipóteses de fundados indícios de condutas previstas nos arts. 186 a 189 do Decreto-Lei ${ }^{0} 7.661$, de 21 de junho de 1945.

A regra, portanto, não é absoluta. A própria lei que rege os planos e seguros privados de saúde estabelece três exceções que farão com que as cooperativas se subordinem à Lei 11.101/2005. Duas observações devem ser feitas quanto à redação deste Art. 23: a primeira é que as cooperativas operadoras de planos de saúde já não se subordinavam ao antigo regime da concordata, que na legislação de 2005 adaptou-se para a recuperação judicial; a segunda é que o inciso III refere-se aos atuais crimes falimentares da lei 11.101/2005, que atualmente estão compreendidos entre os arts.168 a 178.

O resultado do estudo mostra dois sinais claros: (1) o porte econômico advém tanto da boa saúde financeira das cooperativas (visto no valor de ativos), ou (2) o colapso financeiro do mesmo (como relatado no patrimônio líquido deficitário). Em qualquer dos dois cenários, o que marca a relevância é o alto fluxo de suas atividades no mercado.

Dois institutos devem ser diferenciados, antes da discussão própria da ineficiência dos procedimentos concursais administrativos: a intervenção extrajudicial e a liquidação extrajudicial. Certo é que ambas são modalidades dos regimes extrajudiciais adotados pelo Estado brasileiro e dirigidas pelas mesmas instituições ligadas à União.

A intervenção extrajudicial possui caráter iminentemente cautelar, tendo por seu objetivo o estudo da crise econômico-financeira da cooperativa, tentando saneá-la no que for cabível (NEGRÃO, 2017).

Por outro lado, a liquidação extrajudicial, nas palavras de Ricardo Negrão (2017, p. 658):

\footnotetext{
A liquidação é o procedimento administrativo que tem a mesma finalidade do instituto da falência: a apuração do passivo, por meio de declarações de crédito, a arrecadação de bens que compõe o ativo da empresa em liquidação, sua avaliação e a venda para o pagamento de credores.
}

O ponto que baliza a diferença destes institutos é o caráter de definitividade. A intervenção extrajudicial busca a solução de medidas no curto prazo como: a nomeação de um interventor e o afastamento temporário de seus administradores (NEGRÃO, 2017). A liquidação extrajudicial é um desdobramento, podendo ser decretada pelo Banco Central com base no Art. 12, “c”, da Lei 6.024/1974, após a vista do relatório ou da proposta do interventor. 
O Banco Central do Brasil é responsável pela liquidação extrajudicial das instituições financeiras no país. No que tange as cooperativas operadoras de planos de saúde, a responsável pela liquidação extrajudicial é a Agência Nacional de Saúde Suplementar (ANS), autarquia federal responsável pela regulação do mercado privado de saúde, cuja previsão está na Lei 9.656/1998.

Para além das competências estabelecidas às entidades para a consecução da liquidação extrajudicial, há uma vertente da doutrina nacional que questiona a imparcialidade e eficiência do Banco Central e da ANS (já que o corte adotado foi apenas das cooperativas de crédito e de operadoras de planos de saúde), na condução dos referidos procedimentos.

Em linhas gerais, a opção pela liquidação extrajudicial, no ordenamento jurídico brasileiro, se deu graças a duas razões: a celeridade e a competência técnica da instituição reguladora. Esse procedimento administrativo, todavia, por correr fora do poder judiciário, tem recebido severas críticas por não observar direitos e garantias fundamentais de índole processual (HERDEM LIMA, 2020).

No pensamento de Jairo Saddi (1999) é marcante a ideia de que a liquidação extrajudicial possui caráter autoritário, dada até as circunstâncias políticas em que fora editada no país. O Banco Central atua como juiz, executor e elaborador dos planos e metas das diversas instituições financeiras do país. Ao interpretar essa reflexão, constata-se a natureza antidemocrática do procedimento concursal guiado pelo poder executivo, já que afasta, em caráter objetivo, a presença do procedimento recuperacional judicial que foi constituído sob à égide da Lei 11.101/2005 e da Constituição Federal de 1988, e que ao longo de toda sua redação prima pelo amplo debate das partes, como ocorre com a previsão da realização da assembleia geral de credores na recuperação judicial (Art.56, $\S 1^{\circ}$ ).

Pode-se argumentar no sentido de que o debate é vazio de sentido, já que a lei falimentar poderá ser aplicada (BERNARDES; SILVA, 2019) ao final da liquidação extrajudicial (Art.21, b, da Lei 6.024/1964). Não há menção, todavia, à recuperação judicial como alternativa a essas cooperativas.

Em suma, a posição privilegiada (HERDEM LIMA, 2020) que o Banco Central assume pode levar a uma séria imparcialidade em seu juízo por duas razões. A primeira é de caráter democrático; a mesma instituição que decreta a liquidação extrajudicial é a mesma que a conduz, conforme destacado anteriormente. A segunda razão é a possível posição do Banco 
Central constar como credor da liquidante quando decretada a falência, já que a chamada iliquidez bancária é um dos motivos para a decretação da liquidação extrajudicial (HERDEM LIMA, 2020). Felipe Herdem Lima (2020, s/p) ainda destaca mais um ponto relevante que retrata essa incompatibilidade:

\begin{abstract}
Entretanto, a Lei no 6.024/74, em seu artigo 34, equipara o Banco Central a "juiz" no decorrer do processo de liquidação, cabendo a ele julgar o valor e a natureza de seu crédito, nos casos em que os sócios ou credores da liquidanda não concordem com a classificação e pagamentos realizados pelo liquidante.
\end{abstract}

A discussão acerca dos privilégios do Banco Central remete a um segundo debate: a ineficiência dos órgãos federais ao conduzir a liquidação extrajudicial; seja o Banco Central, seja a ANS.

Estela Caparelli e Leonardo Souza (2001, s/p) constatam um desses exemplos, com a perda de ativos pelo BC que não serão pagos:

\begin{abstract}
As dívidas e obrigações (passivos) dos nove maiores bancos com liquidação em curso somavam, em dezembro do ano passado, $\mathrm{R} \$ 43$ bilhões. Desse total, caberiam ao BC R \$ 30,5 bilhões. Ou seja, dinheiro que a autoridade monetária injetou nessas instituições, tanto pelo Proer como por linhas de assistência financeira, e que deveria receber de volta. No entanto o $\mathrm{BC}$ calcula que pelo menos $\mathrm{R} \$ 9$ bilhões (o que daria para comprar um Banespa) já foram perdidos. Isto é, empréstimos que dificilmente serão pagos. No balanço de dezembro de 2000, o BC lançou esse valor como provisão para créditos de liquidação duvidosa.
\end{abstract}

Em um exemplo prático: “O caso do Banco Nacional é o mais emblemático. Ao todo, o $\mathrm{BC}$ injetou na instituição $\mathrm{R}$ \$ 15,537 bilhões. Mas considera que $\mathrm{R}$ \$ 5,015 bilhões, correspondentes a um terço dos créditos, já se foram” (CAPARELLI; SOUZA, 2001).

Wladimir Gramacho (2001, s/p), em matéria jornalística, traz à luz uma investigação sobre a perda de $\mathrm{R} \$ 32$ milhões de reais na liquidação judicial do Banco Progresso. Os dois principais argumentos utilizados são o destino do dinheiro e as despesas excessivas:

O ex-liquidante Willian Emediato "apresentou à perícia contábil somente um demonstrativo dos recursos obtidos do FGC, suas respectivas atualizações monetárias e o saldo final de $\mathrm{R} \$ 32.646 .943,32$ ", informou o auditor Alexandre Pimenta Gonçalves, que investigou as contas do banco a pedido da juíza. Faltou, segundo relatório da auditoria, comprovar o destino que foi dado a esse montante extremamente exorbitante, ou seja, comprovar os pagamentos efetuados aos efetivos credores do banco falido.

Durante a administração do Banco Central, os gastos mensais eram de $\mathrm{R} \$ 600$ mil, segundo relatório do síndico da massa falida, Osmar Corrêa Lima. Quando o trabalho passou para a Justiça, as despesas caíram para $\mathrm{R} \$ 100$ mil.

A ANS também não foge à regra. Ligia Formenti (2001, s/p) destaca que:

Até agora, a ANS conseguiu reaver menos de $1 \%$ do total do dinheiro repassado: R\$ 304, 7 mil. A quantia foi paga por 6 das 170 operadoras que estavam em direção 
fiscal, uma espécie de intervenção prevista em lei, que a ANS declara para as operadoras com as contas em desequilíbrio. Dos recursos passados para 339 empresas em liquidação extrajudicial, nada foi devolvido.

Por fim, e com sustento dos argumentos desenvolvidos ao longo deste capítulo, é inegável a conclusão de que o procedimento de liquidação extrajudicial realizado pelos órgãos federais é autoritário e constituído sob uma base história antidemocrática de concentração econômica na mão do Estado. Além disso, não prima pelo amplo debate entre as partes envolvidas e tampouco produz resultados que sejam eficientes às liquidandas.

O regime jurídico a qual as cooperativas, objeto deste estudo, estão submetidas, impossibilita sua efetiva recuperação, uma vez que quando se afasta a possiblidade da recuperação sob a responsabilidade do Poder Judiciário na apreciação desta matéria, está se afastando, de certa forma, toda a capacidade negocial da cooperativa com seus credores e o caráter constitucional que envolve o procedimento recuperacional. Um bom exemplo que justifica essa afirmação é a presença de vários agentes na formação da recuperação judicial: assembleia geral de credores, magistrado, administrador judicial, ministério público e a própria recuperanda, e não de apenas um. Assim como a possibilidade do cram down (Art.58, $\S 1^{\circ}$ da lei $\left.11.101 / 2005\right)$ em nome do princípio da preservação da empresa.

\section{O PROTAGONISMO DOS DIREITOS FUNDAMENTAIS NO CENÁRIO RECUPERACIONAL DAS COOPERATIVAS}

Os direitos fundamentais compõem o núcleo de cláusulas pétreas da CRFB/1988 (SARLET; MARINONI; MITIDIERO, 2017). Em um cenário de concretização necessária dos direitos fundamentais e de constitucionalização do direito privado; o direito comercial, ainda que lhe falte dignidade científica (CHAVES, 2019), deve utilizar seus institutos para romper com um cenário de centralização econômica e efetivar os direitos fundamentais.

Apesar da designação genérica do termo efetivar, em última instância o que se quer, é que aqueles que mais necessitem dos serviços prestados pelas cooperativas possam ter acesso a estes no momento de crise econômico-financeira.

As cooperativas operadoras de planos de saúde trabalham diretamente com a tutela do direito à saúde, com o espaço deixado à iniciativa privada pela CRFB/1988. Assim como as cooperativas de crédito trabalham com o direito ao consumo, que é tido por uma forma de expressão dos direitos da personalidade (DEBS; HIRONAKA, 2002) e estes compõem o rol dos direitos fundamentais (NASCIMENTO, 2016). 
Por trabalharem com direitos tão inatos à condição da pessoa humana, principalmente na sociedade capitalista moderna, as cooperativas de relevante porte econômico devem ser tratadas em sua fase de colapso com os remédios mais aptos a ampliarem a participação ativa dos cooperados no procedimento, já que esses são os credores mais dependentes de sua atividade. O único procedimento capaz de proporcionar tal hipótese é a recuperação judicial, caso a cooperativa, obviamente, seja viável.

$\mathrm{O}$ argumento de que a vedação à recuperação judicial é coerente (já que poderia haver abusos em virtude do interesse nacional da atividade), é contraposto pela presença do ministério público (como fiscal da lei) e do magistrado que está adstrito a observar a legalidade do procedimento judicial.

Não é coerente tentar conciliar a recuperação das cooperativas que lidam diretamente com a efetivação dos direitos fundamentais com procedimentos administrativos ligados a apenas uma organização, sem o devido contraditório e ampla defesa.

\section{CONCLUSÃO}

Conclui-se, diante de todos os argumentos e dados considerados neste trabalho, que a evolução histórica do direito comercial permitiu que surgisse um novo fenômeno para sua observação, ocorrendo a passagem dos antigos perfis da empresa de Asquini para o mercado como uma instituição jurídica (GRAU, 2008).

Diante desse cenário evolutivo, deve-se dar atenção ao conceito de atividade econômica ao invés de adotar os critérios já ultrapassados da lei falimentar. Em um cenário nacional onde está em vigência uma Constituição Federal democrática, e que concebeu como seu referencial os direitos e garantias fundamentais, os institutos do direito comercial, mais especificamente, a recuperação judicial devem auxiliar os agentes econômicos a sair de suas crises econômico-financeiras.

As cooperativas que possuem um relevante porte econômico (neste trabalho: as cooperativas de crédito e cooperativas operadoras de planos de saúde) lidam com uma relevante parcela do mercado; estando diretamente ligados aos direitos fundamentais à saúde e ao consumo.

No atual cenário, essas cooperativas se submetem aos regimes da intervenção e liquidação extrajudicial, que possuem caráter marcadamente antidemocrático, uma vez que o 
mesmo órgão federal (Banco Central ou a ANS) é o responsável por decretar e conduzir o procedimento concursal administrativo.

Por essa razão, a possibilidade do deferimento de recuperação judicial a essas cooperativas que atuam em mercados fortemente regulados pelo Estado brasileiro, não é só apenas um remédio para a solução do colapso, mas também uma forma de enquadrá-las em um procedimento judicial que valorize o contraditório e a ampla defesa como direitos fundamentais processuais (SARLET; MARINONI; MITIDIERO, 2017), que estejam sob a fiscalização de diferentes servidores públicos com limites de poder, como: o magistrado e o promotor e justiça, que ofereçam uma real oportunidade de recuperação, em virtude da ineficiência das instituições reguladoras, e que dê voz aos cooperados, que em última instância, são os credores que mais necessitam de seus serviços e que têm seus direitos fundamentais violados pela impossibilidade da prestação mínima da referida cooperativa.

\section{REFERÊNCIAS BIBLIOGRÁFICAS:}

ANDRIGHI, Nancy. Autonomia de Direito Cooperativo. In: ANDRIKRUEGER, Guilherme (Coord.) Cooperativismo e o novo código civil. Belo Horizonte: Mandamentos, 2003.

ASCARELLI, Tullio. Iniciação ao estudo do direito mercantil. Sorocaba/SP: Ed. Minelli, 2007.

O empresário (L'IMPREDITORE). Tradução: Fábio Konder Comparato. Revista de Direito Mercantil. Vol.109. p.183/189. São Paulo: Malheiros, 1998.

BERNARDES, Flávio Couto; SILVA, Suélen, Marine. Aspectos controversos sobre a (in) aplicabilidade do regime falimentar às cooperativas de crédito. Revista Brasileira de Direito Empresarial. v. 5, n. 2. p. 58 a 76. Santa Catarina: CONPEDI, 2019. Disponível em: 10.26668/IndexLawJournals/2526-0235/2019.v5i2.5967 (Acesso em: 03 março 2020).

BIALOSKORSKI, Neto Sigismundo. Aspectos Econômicos das Cooperativas. Belo Horizonte: Mandamentos, 2006.

BRASIL. Lei 4.595/64: Dispõe sobre a Política e as Instituições Monetárias, Bancárias e Creditícias, Cria o Conselho Monetário Nacional e dá outras providências. Disponível em: http://www.planalto.gov.br/ccivil_03/leis/14595.htm (Acesso em 12 de março 2020).

BRASIL. Lei 6.024/74: Dispõe sobre a intervenção e a liquidação extrajudicial de instituições financeiras, e dá outras providências. Disponível em: http://www.planalto.gov.br/ccivil_03/LEIS/L6024.htm (Acesso em 03 de fev. 2020). 
BRASIL. Lei 9.656/98: Dispõe sobre os planos e seguros privados de assistência à saúde. Disponível em: http://www.planalto.gov.br/ccivil_03/leis/19656.htm (Acesso em 04 março 2020).

BRASIL. Lei 11.101/05: Regula a recuperação judicial, a extrajudicial e a falência do empresário e da sociedade empresária. Disponível em: http://www.planalto.gov.br/ccivil_03/_ato2004-2006/2005/lei/111101.htm (Acesso em 02 de fev. 2020).

CAPARELLI, Estela; SOUZA, Leonardo. Liquidação de banco se arrasta e falha, diz BC. On-line. Folha de São Paulo: São Paulo, 2001. Disponível em: https://www1.folha.uol.com.br/fsp/dinheiro/fi1706200113.htm. Acesso em 02 jul.2020.

CASTRO, Carlos Alberto Farracha de. Fundamentos do direito falimentar. 2. ed. Curitiba: Juruá, 2006, p. 72.

CHAVES, Vinicius Figueiredo. EM BUSCA DA DIGNIDADE CIENTÍFICA DO DIREITO COMERCIAL BRASILEIRO. Revista Brasileira de Direito Empresarial. v. 5, n. 2. p. 77 a 97. Santa Catarina: CONPEDI, 2019. Disponível em: https://www.indexlaw.org/index.php/direitoempresarial/article/view/5985 (Acesso em: 03 março 2020).

COELHO, Fábio Ulhoa. Parecer: O alcance de alguns dos dispositivos do novo Código Civil (Lei $\mathrm{n}^{\mathbf{0}}$ 10.406, de 10 de janeiro de 2002) atinentes ao direito de empresa que dizem respeito ao registro das sociedades simples. p.11. São Paulo: 2003.

DEBS, Newman de Faria; HIRONAKA, Giselda Maria Fernandes Novaes. O direito ao consumo: forma de expressão dos direitos da personalidade. São Paulo: Universidade de São Paulo, 2002.

DE PLÁCIDO E SILVA, Vocabulário Jurídico. 15. Ed. Rio de Janeiro: Forense, 1998.

DEL FIACO. Juliana Luiza Moreira. Das relações humanas a importância do fator humano nas instituições de ensino superior. Revista Brasileira de Administração, 2006. pág. 59-77.

FORGIONI, Paula A. A evolução do direito comercial brasileiro: Da mercancia ao mercado. $3^{a}$ ed. São Paulo: Editora Revista dos Tribunais, 2016.

Paula Forgioni: Aula magna. In: Nota Bene. INSPER: São Paulo, 2018. Disponível em: https://www.youtube.com/watch?v=ul2s1seB9H0\&t=754s (Acesso em 07 março 2020).

FORMENTI, Ligia. Após socorro a planos de saúde em crise financeira, ANS não é ressarcida. on-line. São Paulo: Estadão, 2011. Disponível em: https://www.estadao.com.br/noticias/geral,apos-socorro-a-planos-de-saude-em-crisefinanceira-ans-nao-e-ressarcida-imp-,716708. Acesso em 02 jul.2020. 
FURQUIM, Maria Cecília de Araújo. A cooperativa como alternativa de trabalho. São Paulo: LTR, 2001.

GAIGER, Luiz Inácio. A economia solidária e a revitalização do paradigma cooperativo. Revista Brasileira de Ciências Sociais. Vol. 28 n. 82. São Paulo, 2013.

GONÇALVES NETO, Alfredo Assis. Direito de Empresa: Comentários aos artigos 966 a 1.195 do Código Civil. p.47. São Paulo: Ed. Revista dos Tribunais, 2000.

GRAMACHO, Wladimir. Liquidante some com R\$ 32mi do Progresso. On-line. São Paulo: Folha de São Paulo, 2001.

GRAU, Eros Roberto. A ordem econômica na Constituição de 1988. 13 $3^{\text {a }}$ ed. São Paulo: Malheiros, 2008.

HARDER, Eduardo. A definição da autonomia privada nas sociedades cooperativas: função social e princípio da democracia. 2005. Dissertação (Mestrado em Direito) Disponível em: https://acervodigital.ufpr.br/bitstream/handle/1884/1839/Eduardo\%20Harder.Dissertacao.Ver sao\%20Final.pdf;jsessionid=6E3FAA78E163FCD5F46ED6ABF13EEE98? sequence $=1$ (Acesso em 08 março 2020).

HERDEM LIMA, Felipe. Parcialidade do Banco Central do Brasil como juízo universal. Rio de Janeiro: JOTA, 2020. Disponível em: https://www.jota.info/opiniao-eanalise/artigos/parcialidade-do-banco-central-do-brasil-como-juizo-universal-11022020 (Acesso em 04 março 2020).

LOPES BECHO, Renato. Elementos do Direito Cooperativo. São Paulo: Dialética, 2003.

NASCIMENTO, Valéria Ribas do. Direitos fundamentais da personalidade na era da sociedade da informação Transversalidade da tutela à privacidade. Revista de informação legislativa, v. 54, n. 213, p. 265-288, jan./mar. Senado Federal: Brasília, 2017.

NEGRÃO, Ricardo. Curso de direito comercial e de empresa - volume 3: recuperação de empresas, falência e procedimentos concursais administrativos. $11^{\text {a }}$ edição. São Paulo: Saraiva, 2017.

PINHO, Diva Benavides. Tipologia cooperativista. São Paulo: CNPQ, $3^{\text {a }}$ ed., 1996.

PONTES DE MIRANDA, F.C. Tratado de Direito Privado - vol. 49. p. 429. Rio de Janeiro: Borsói, 1965.

PRADO, Flávio Augusto Dumont. Tributação das cooperativas à luz do direito cooperativo. $2^{a}$ tir.. Curitiba: Jaruá, 2005. 
SADDI, Jairo. Algumas propostas de mudança para a Lei no 6.024. In: Intervenção e liquidação extrajudicial no sistema financeiro nacional. 25 anos da Lei n. 6.024/74. São Paulo: Texto Novo/UNICID, 1999, pp. 291-319.

SARLET, Ingo Wolfgang; MARINONI, Luiz Guilherme; MITIDIERO, Daniel. Curso de direito constitucional. $6^{\mathrm{a}}$ ed. São Paulo: Saraiva, 2017.

SISTEMA OCB. Números do cooperativismo brasileiro. 2018. disponível em: https://www.ocb.org.br/numeros (Acesso em: 07 março 2020).

SZTAJN, Rachel. Teoria Jurídica Da Empresa: Atividade Empresária e Mercados. $2^{\mathrm{a}}$ ed. São Paulo: Atlas, 2010.

TARTUCE, Flávio. Manual de direito civil: volume único. São Paulo: Ed. Método, 2017.

TJRJ. Sentença: Processo n ${ }^{\circ}$ 0022156-21.2018.8.19.0042. Juiz: Jorge Luiz Martins Alves. DJ 18/10/2018. http://www1.tjrj.jus.br/gedcacheweb/default.aspx?GEDID=000419C40ABB98F759EA4E784 E6F34853294C5091315252A (Acesso em 15 março 2020).

VALOR ECONÔMICO. Ranking dos 50 maiores planos de saúde. 2018. s/p. Disponível em: https://www.valor.com.br/valor1000/2019/ranking50maioresplanosdesaude (Acesso em 03 março 2020).

VALOR ECONÔMICO. Ranking dos 100 maiores bancos. 2018. s/p. Disponível em: https://www.valor.com.br/valor1000/2019/ranking100maioresbancos (Acesso em 05 março 2020). 